\title{
Preparation and Characterization of UV-Cured Hybrid Polyvinyl Alcohol Nanofiber Membranes by Electrospinning
}

\author{
Bihter Zeytuncu ${ }^{\text {a*, Süleyman Akman }}$, Onuralp Yucel', MemetVezir Kahraman \\ a Istanbul Technical University, Applied Research Center of Materials Science \\ and Production Technology, 34469, Istanbul, Turkey \\ ${ }^{\mathrm{b}}$ Istanbul Technical University, Faculty of Science and Letters, \\ Department of Chemistry, 34469, Istanbul, Turkey \\ 'Istanbul Technical University, Faculty of Chemical and Metallurgical Engineering, \\ 34469, Istanbul, Turkey \\ ${ }^{\mathrm{d}}$ Marmara University, Faculty of Science and Letters, Department of Chemistry, 34722, Istanbul, Turkey
}

Received: May 28, 2013; Revised: March 9, 2014

\begin{abstract}
The present study investigated the possibility of preparing polyvinyl alcoholic (PVA) organicinorganic hybrid nanofiber membranes by electrospinning with UV irradiation. To this end, PVA, PVA/SiO $\mathrm{SiO}_{2}$ organic-inorganic hybrid obtained with Geniosil@ XL 33 as a $\mathrm{SiO}_{2}$ source, and imidazolefunctionalized mesoporous $\mathrm{PVA} / \mathrm{SiO}_{2} / \mathrm{N}=\mathrm{N}$ nanofiber membranes were synthesized. These membranes were characterized by Fourier transform infrared spectroscopy, scanning electron microscopy, thermogravimetric-differential thermal analysis, and Brunauer-Emmett-Teller analysis. According to results, fine polymeric nanofibers were obtained in the size range of 100-200 nm for pure PVA nanofibers and $150-250 \mathrm{~nm}$ for $\mathrm{PVA} / \mathrm{SiO}_{2}$ hybrid nanofibers, while imidazole-functionalized PVA/ $\mathrm{SiO}_{2}$ nanofibers were less than $100 \mathrm{~nm}$. The membranes produced are suitable for use in various applications, including filtration and adsorption, in the biomedical and textile industries, among others.
\end{abstract}

Keywords: electrospinning, nanofiber, UV-curable, hybrid material, polyvinyl alcohol

\section{Introduction}

During the past decade, nanofiber has received extensive use in diverse industrial applications because of its extraordinary properties, including its light weight, large surface-area-to-volume ratio, porous structure, and superior mechanical properties ${ }^{1-4}$. Recent developments to improve the chemical properties in nanofiber technology have laid the foundation for current opportunities to revolutionize the material by combining the desirable properties of organic polymers (e.g., elasticity and processability) and inorganic solids (e.g., chemical inertness and thermal resistance) ${ }^{5}$. By combining all of the above properties, organicinorganic hybrid nanofiber can used in various products, such as textiles, optical devices, membranes, sensors, tissue engineering scaffolds, and catalytically synthesized nanofiber, among others ${ }^{6}$.

PVA is a semi-crystalline hydrophilic polymer with good chemical and thermal stability. It is a highly biocompatible, highly water-permeable, nontoxic polymer that can be easily processed. Furthermore, PVA is known to interact with other organic and inorganic materials ${ }^{5}$. PVA with functional groups is useful in practical investigations of functional polymers given its easy preparation as a bulk material and in films and fibers ${ }^{7-9}$. PVA interacts with other materials in electrode position to form a mixed membrane within a polymer matrix. At high temperatures, mesoporous PVA/silica nanofiber membranes can be synthesized;

*e-mail: bihterzeytuncu@gmail.com however, such temperatures remove the organic groups from the matrix, which renders the nanofiber membranes unsuitable for application in water treatment ${ }^{10-13}$.

Electrospinning is a simple, inexpensive, convenient, effective, and widely used technique for generating nanofiber membrane materials that has recently attracted a great deal of attention. In electrospinning, a strong electrostatic force produced by high static voltage is used to create an electrically charged jet of polymer solution that should be placed in a container with a nozzle $1 \mathrm{~mm}$ in diameter. During the process, an oppositely charged supply is connected to the needle and grounded collector plate, and as the magnitude of voltage rises, the hemispherical surface of the liquid lengthens to form a Taylor cone and to produce fiber with nano dimensions. After critical voltage is applied, the electrostatic force overcomes the surface tension, and the charged jet is ejected from the tip of the Taylor cone, which undergoes a process of elongation and evaporation that produces polymer nanofiber ${ }^{11,14-16}$.

This study sought to synthesize an effective nanoscale fiber membrane by electrospinning with UV irradiation and, in the process, compare the three organic-inorganic hybrid nanofiber membranes, the optimal conditions for which this paper reports. To this end, pure PVA nanofiber membrane was compared to both $\mathrm{PVA} / \mathrm{SiO}$ and imidazole-functionalized $\left(\mathrm{PVA} / \mathrm{SiO}_{2} / \mathrm{N}=\mathrm{N}\right)$ hybrid nanofiber membranes, all of which were evaluated by 
Fourier transform infrared spectroscopy (FTIR), scanning electron microscopy (SEM), thermogravimetric-differential thermal analysis (TG-DTA), and Brunauer-Emmett-Teller (BET) analysis.

\section{Material and Methods}

\subsection{Experimental procedures}

PVA (87-89\% hydrolyzed, Mw 146000-186000 g; Sigma- Aldrich, St. Louis, MO, USA), $N$-vinylimidazole (NVI; Alfa Aesar, Ward Hill, MA, USA), and, as a $\mathrm{SiO}_{2}$ source, methacryloxymethyltrimethoxysilane (MMTMS; Geniosil@ XL 33, Wacker Chemie AG, Munich, Germany) were used in this study, as well as radical photoinitiator 2-hydroxy-2-methyl-1-phenyl-1-propan-1-one (Darocur ${ }^{\circledR}$ 1173, Aldrich-Sigma) and both hydrochloric acid and ethyl alcohol (Merck, Whitehouse Station, NJ, USA). Deionized (DI) water was also used throughout the study.

\subsection{Preparation of PVA spinning solutions}

10 wt.\% PVA solutions were prepared by dissolving PVA in deionized water to obtain the ideal thin and uniform PVA fiber ${ }^{18}$. PVA powder was slowly stirred into the deionized water at room temperature for $30 \mathrm{~min}$. The temperature was next gradually raised to $85{ }^{\circ} \mathrm{C}$ while the mixture was constantly stirred for $3 \mathrm{~h}$ to homogenize the solution. The transparent solutions obtained were refrigerated overnight. Next, MMTMS (0.023 mol) and NVI (0.023 mol) were vigorously stirred into $50 \mathrm{~mL}$ PVA solutions to homogenize the PVA/MMTMS solutions. Upon adding $3 \mathrm{wt} \%$ Darocur ${ }^{\circledR}$ 1173 as a photoinitiator into the prepared solutions, the solutions were immediately electrospun. The components of all nanofiber membranes appear in Table 1.

\subsection{Preparation of nanofiber membranes}

The prepared solutions were loaded separately into a syringe, to which the positive terminal of a high-voltage power supply was connected, while the negative terminal was connected to a conductive drum covered with aluminum foil as a fiber collector. A voltage of $20 \mathrm{kV}$ with a tip-totarget distance of $15 \mathrm{~cm}$ at a flow rate of $3 \mathrm{~mL} / \mathrm{h}$ was applied to the solution being irradiated with a high pressure UV lamp $\left(\lambda_{\max }=365 \mathrm{~nm}\right.$, OSRAM 300w,). During the electrospinning process (Figure 1), a dense web of fibers was collected on the aluminum foil and first dried for $12 \mathrm{~h}$ at $100{ }^{\circ} \mathrm{C}$ in a vacuum. The nanofiber membranes obtained were refluxed in ethanol/ $\mathrm{HCl}$ (molar ratio $10: 1$ ) for $24 \mathrm{~h}$ at $70{ }^{\circ} \mathrm{C}$ to remove the template and finally dried for $6 \mathrm{~h}$ at $30^{\circ} \mathrm{C}$ in a vacuum.

\subsection{Characterization}

FTIR spectrum of prepared membranes was obtained with FTIR spectrometer (Spectrum 100, PerkinElmer, Waltham, MA, USA) in the wave number region of $4000-400 \mathrm{~cm}^{-1}$ to define the characteristic peaks of functional groups of the nanofiber membranes. The surface morphology of the electrospun nanofiber was examined with SEM (JEOL JSM 7000F). The specific surface area and pore volume were determined using BET analysis (ASAP 2020). The thermal behavior of the PVA based fibers was
Table 1. The components of raw materials used in the synthesis of nanofiber membranes.

\begin{tabular}{lcccc}
\hline \multicolumn{1}{c}{ Gels } & $\begin{array}{c}\text { 10 Wt. \% } \\
\text { PVA }(\mathbf{g})\end{array}$ & $\begin{array}{c}\text { MMTMS } \\
(\mathbf{g})\end{array}$ & NVI (g) & $\begin{array}{c}\text { Darocur® } \\
\mathbf{1 1 7 3}(\mathbf{g})\end{array}$ \\
\hline $\mathrm{PVA}$ & 50 & 0.023 & 0.00 & 3 \\
$\mathrm{PVA} / \mathrm{SiO}_{2}$ & 50 & 0.023 & 0.00 & 3 \\
$\mathrm{PVA} / \mathrm{SiO}_{2} / \mathrm{N}=\mathrm{N}$ & 50 & 0.023 & 0.023 & 3 \\
\hline
\end{tabular}

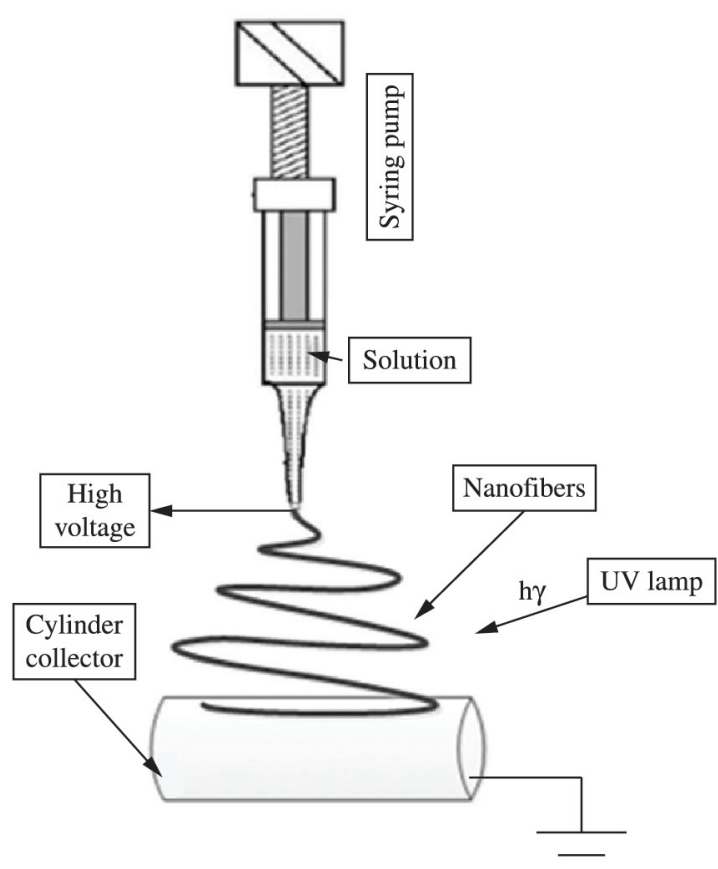

Figure 1. Schematic diagram of electrospinning process.

evaluated by TG-DTA (Diamond TG-DTA, PerkinElmer). Nanofiber membranes were heated from 30 to $750^{\circ} \mathrm{C}$ at a rate of $10^{\circ} \mathrm{C} / \mathrm{min}$ under air.

\section{Results and Discussion}

UV irradiation nanofibers were prepared by electrospinning under UV irradiation at a voltage of $20 \mathrm{kV}$ with a tip-to-target distance of $15 \mathrm{~cm}$ and flow rate of $3 \mathrm{~mL} / \mathrm{h}$. They were subsequently extracted with ethanol/ $\mathrm{HCl}$ (molar ratio 10:1) for $24 \mathrm{~h}$.

Figure 2 shows the FTIR spectra for the pure PVA nanofiber, $\mathrm{PVA} / \mathrm{SiO}_{2}$ nanofiber, and the imidazolefunctionalized hybrid nanofiber $\left(\mathrm{PVA} / \mathrm{SiO}_{2} / \mathrm{N}=\mathrm{N}\right)$. The FTIR spectrum of pure PVA nanofiber (Figure 2a) exhibited a very strong, broad peak at $3300 \mathrm{~cm}^{-1}$, given the hydroxyl $(\mathrm{OH})$, and at $2942 \mathrm{~cm}^{-1}$, given $\mathrm{CH}_{2}$ asymmetric stretching. The peak observed at $1088 \mathrm{~cm}^{-1}$ was attributed to the presence of terminal polyvinyl groups, while $1735 \mathrm{~cm}^{-1}$ indicated the carbonyl $(\mathrm{C}=\mathrm{O})$ stretching bond ${ }^{5,17}$. In the FTIR spectrum of $\mathrm{PVA} / \mathrm{SiO}_{2}$ nanofiber (Figure $2 \mathrm{~b}$ ), the bonds recorded at 941 and $1100 \mathrm{~cm}^{-1}$ derived from vibrations of Si-O and $\mathrm{Si}-\mathrm{O}-\mathrm{Si}$ stretching. The peak at $1248 \mathrm{~cm}^{-1}$ was due to $\mathrm{Si}-\mathrm{CH}_{2}$, and the vibration of $\mathrm{C}=\mathrm{O}$ appeared at $1724 \mathrm{~cm}^{-15,18-20]}$. The FTIR 
spectrum in Figure 2c shows the characteristic bands for imidazole group vibrations at $1639 \mathrm{~cm}^{-1}(\mathrm{C}=\mathrm{N}$ stretching), $1248 \mathrm{~cm}^{-1}$ (C-N stretching in the imidazole ring), and $1116 \mathrm{~cm}^{-1}(\mathrm{C}-\mathrm{N} \text { stretching })^{21}$. FTIR analysis confirmed that the condensation reaction was successfully performed between PVA, MMTMS and NVI.

SEM images of nanofiber membranes appear in Figure 3. As a result of the strong interaction between the inorganic and organic phases, both the spinning behavior and morphology of the hybrid fibers differ significantly from that of pure PVA fiber. Since the morphology of pure PVA nanofiber exhibited a smooth surface, the PVA/SiO, with imidazole tended to form beads (Figure $3 \mathrm{e}$ and $\mathrm{f}$ ). By comparison, the $\mathrm{PVA} / \mathrm{SiO}_{2} / \mathrm{N}=\mathrm{N}$ nanofiber was more densely packed. The average diameter of pure PVA nanofiber fell between 100 and $200 \mathrm{~nm}$ (Figure 3b), while that of the

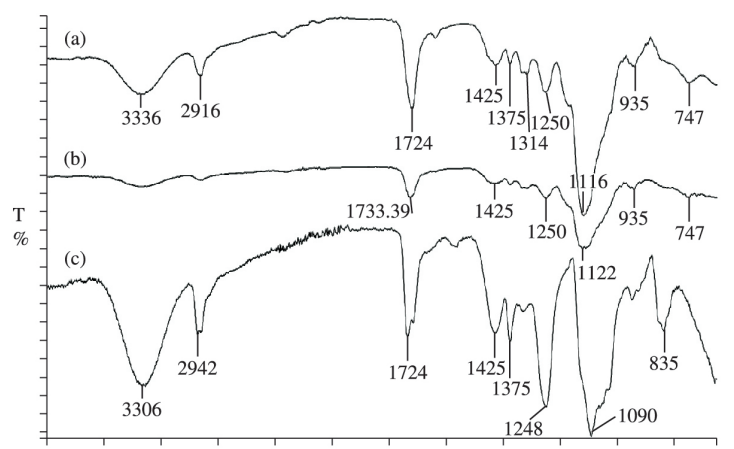

$\begin{array}{lllllllllllll}4000 & 3600 & 3200 & 2800 & 2400 & 2000 & 1800 & 1600 & 1400 & 1200 & 1000 & 800 & 650\end{array}$ Wavelength $\left(\mathrm{cm}^{-1}\right)$

Figure 2. FTIR spectra of (a) PVA, (b) $\mathrm{PVA} / \mathrm{SiO}_{2}$ and (c) PVA/ $\mathrm{SiO}_{2} / \mathrm{N}=\mathrm{N}$ nanofiber membranes.
PVA/SiO hybrid fell between 150-250 nm (Figure 3d) and that of the PVA/SiO $/ \mathrm{N}=\mathrm{N}$ did not exceed $100 \mathrm{~nm}$. Table 2 shows the BET surface area and the pore volume of extracted nanofiber membranes; clearly, both aspects increased as the PVA was modified.

All nanofiber membranes were analyzed by TG-DTA in air reaching $750{ }^{\circ} \mathrm{C}$ in order to study their thermal behaviors. Figure 4 presents the TG-DTA curves of the nanofiber membranes 4 . For pure PVA nanofiber membrane, the TG curve revealed a peak at $52{ }^{\circ} \mathrm{C}$ due to moisture vaporization. The first decomposition temperature $\left(235^{\circ} \mathrm{C}\right)$ coincided with $5 \%$ weight loss, after which a rapid weight loss of $83 \%$ occurred as the temperature rose to $495{ }^{\circ} \mathrm{C}$. Complete decomposition of the nanofiber occurred from 626 to $660{ }^{\circ} \mathrm{C}$ with weight losses of 96 and $98 \%$, respectively.

On the DTA curve, endothermic peaks were observed at 289 and $450{ }^{\circ} \mathrm{C}$, while exothermic peaks occurred at $50,270,362,434$, and $496{ }^{\circ} \mathrm{C}$. There was a sharp, large exothermic peak at $495{ }^{\circ} \mathrm{C}$ concurrent with a weight loss of approximately $88 \%$, which indicated the complete decomposition of the nanofiber that agrees with the TG curve (Figure 4) ${ }^{22,23}$. As shown in Figure 4b, rapid weight loss occurred from 50 to $150{ }^{\circ} \mathrm{C}$ in the thermal curves of the $\mathrm{PVA} / \mathrm{SiO}_{2}$ hybrid nanofiber due to the polycondensation of

Table 2. Physical properties of nanofiber membranes.

\begin{tabular}{lccc}
\hline $\begin{array}{c}\text { Nanofiber } \\
\text { membrane }\end{array}$ & $\begin{array}{c}\text { Surface area } \\
\left(\mathbf{m}^{2} / \mathbf{g}\right)\end{array}$ & $\begin{array}{c}\text { Pore volume } \\
\left(\mathbf{c m}^{3} / \mathbf{g}\right)\end{array}$ & $\begin{array}{c}\text { Nanofiber } \\
\text { diameter } \\
(\mathbf{n m})\end{array}$ \\
\hline $\mathrm{PVA}$ & 30.4 & 0.031 & $100-200$ \\
$\mathrm{PVA} / \mathrm{SiO}_{2}$ & 316.4 & 0.302 & $150-250$ \\
$\mathrm{PVA} / \mathrm{SiO}_{2} / \mathrm{N}=\mathrm{N}$ & 386.7 & 0.365 & $80-110$ \\
\hline
\end{tabular}

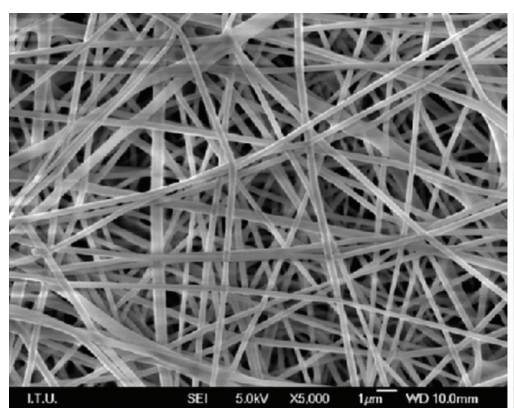

(a)

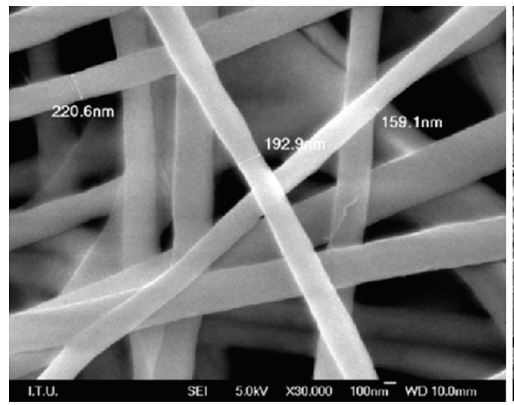

(d)

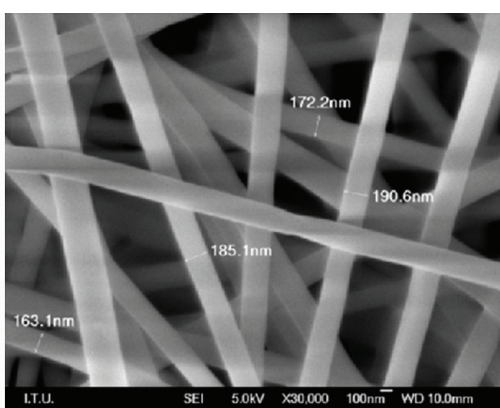

(b)

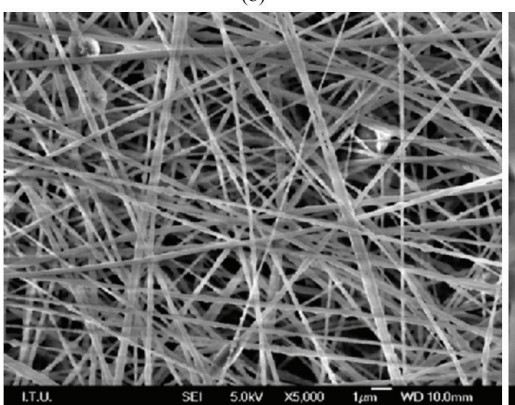

(e)

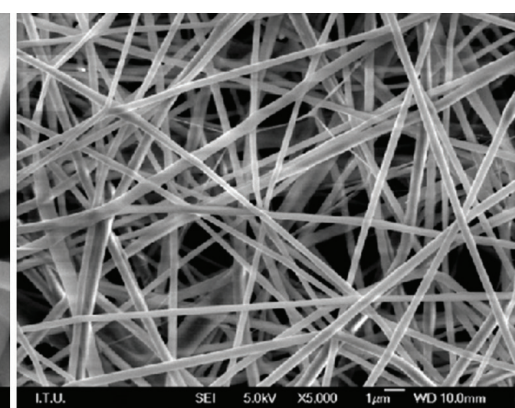

(c)

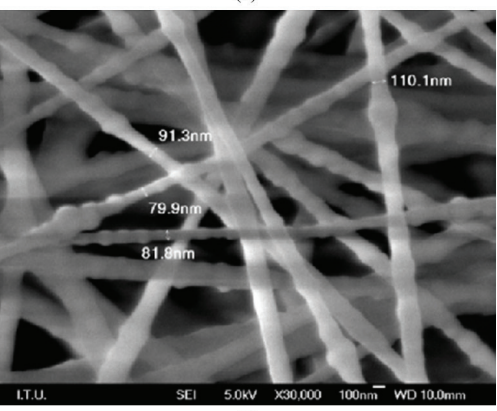

(f)

Figure 3. SEM images of (a) and (b) pure PVA nanofiber; (c) and (d) $\mathrm{PVA} / \mathrm{SiO}_{2}$, and (e) and (f) $\mathrm{PVA} / \mathrm{SiO}_{2} / \mathrm{N}=\mathrm{N}$ nanofiber membranes. 
the silica matrix. After this point, $85 \%$ weight loss slowly occurred as temperatures rose to $540{ }^{\circ} \mathrm{C}$. The last thermal degradation of the organic fraction occurred at $620^{\circ} \mathrm{C}$ with a weight loss of $90 \%$. The residue at $620{ }^{\circ} \mathrm{C}$ was white, and in this case, no residual carbon was left ${ }^{24}$.

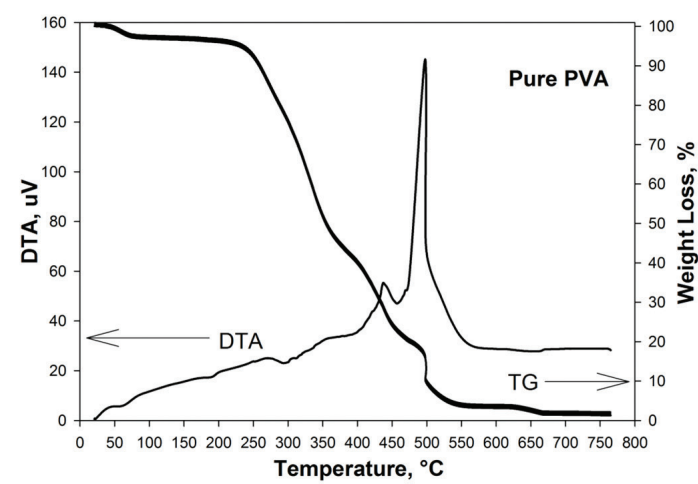

(a)

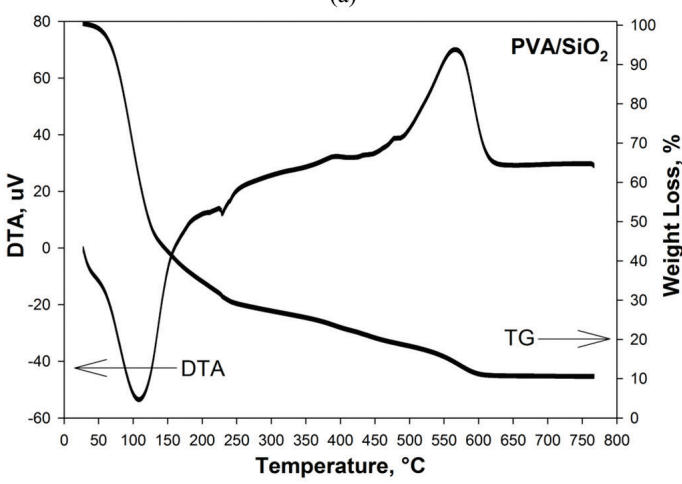

(b)

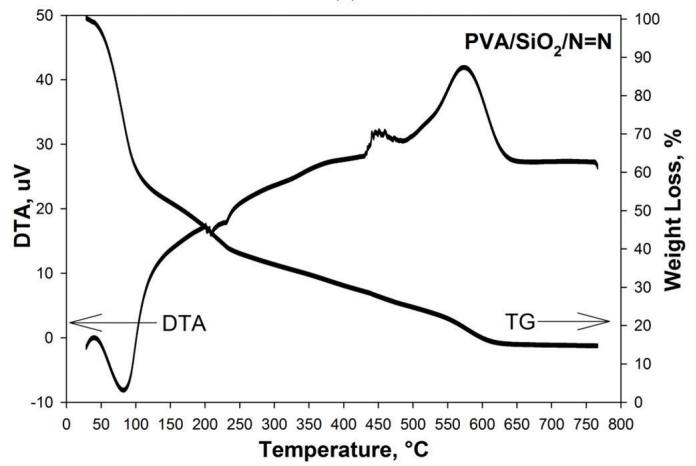

(c)

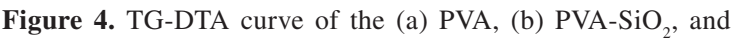
(c) $\mathrm{PVA} / \mathrm{SiO}_{2} / \mathrm{N}=\mathrm{N}$ nanofiber membranes.
Also on the DTA curve, endothermic peaks were observed at 106,230 , and $485{ }^{\circ} \mathrm{C}$, while exothermic peaks occurred at $221,390,478$, and $565{ }^{\circ} \mathrm{C}$. As shown in Figure $4 \mathrm{c}$, The $\mathrm{PVA} / \mathrm{SiO}_{2} / \mathrm{N}=\mathrm{N}$ hybrid nanofiber membrane exhibited large thermal degradations from approximately 100 to $620{ }^{\circ} \mathrm{C}$. The improvement in thermal stability of the composites suggests the prevention of thermal motions of the PVA chains given the cross-linking with the imidazole and silica network. A small endothermic peak on the DTA curve was observed at approximately $80^{\circ} \mathrm{C}$, in addition to a broad exothermic peak associated with weight loss from approximately 100 to $570{ }^{\circ} \mathrm{C}$. Two small exothermic peaks at $450{ }^{\circ} \mathrm{C}$ and $572{ }^{\circ} \mathrm{C}$ on the DTA curve could be ascribed to the thermal decomposition of $\mathrm{PVA} / \mathrm{SiO}_{2} / \mathrm{N}=\mathrm{N}^{21}$.

\section{Conclusion}

This study investigated the possibility of PVA organicinorganic hybrid nanofiber membranes by electrospinning combined with UV irradiation. Nanofiber membranes were synthesized by optimizing electrospinning process parameters. While collected on the aluminum foil at $20 \mathrm{kV}$, the distance between capillary and collecting drum optimized at $15 \mathrm{~cm}$ and a flow rate of $3 \mathrm{~mL} / \mathrm{h}$ for spinning. FTIR analysis confirmed the presence of $\mathrm{SiO}_{2}$ and an imidazole ring in the membrane, as well as the formation of a $\mathrm{PVA} / \mathrm{SiO}_{2} / \mathrm{N}=\mathrm{N}$ membrane. SEM images revealed that the average diameter of nanofiber in PVA membranes were greater than that in the modified PVA nanofiber membranes. The thermal stability of the nanofiber membranes was assessed by TG-DTA analysis; these membranes achieved thermal stability at approximately $450{ }^{\circ} \mathrm{C}$.

The hybrid nanofiber membranes, which have a mesoporous structure and both a large surface area and pore volume, have better physical and chemical properties than pure PVA nanofiber. Consequently, the membranes produced are suitable for use in various industrial applications, including filtration and adsorption, in the biomedical and textile industries, among others.

\section{Acknowledgements}

This study is a part of my PhD dissertation at the Istanbul Technical University. The authors wish to thank the Istanbul Technical University for financial support under BAP project 36460. Grateful acknowledgements are due to University of Marmara for synthesis of membranes via Electrospinning technique. 


\section{References}

1. Dzenis Y. Spinning continuous fibers for Nanotechnology. Science. 2004; 304:1917-1919. PMid:15218134. http://dx.doi. org/10.1126/science.1099074

2. Zhang DM and Chang J. Electrospinning of Three-Dimensional Nanofibrous Tubes with Controllable Architectures. Nano Letters. 2008; 8:3283-3287. PMid:18767890. http://dx.doi. org/10.1021/n1801667s

3. Aluigi A, Corbellini A, Rombaldoni F and Mazzuchetti G. Wool-derived keratin nanofiber membranes for dynamic adsorption of heavy-metal ions from aqueous solutions. Textile Research Journal. 2013; 83(15):1574-1586. http://dx.doi. org/10.1177/0040517512467060

4. Feng C, Khulbe KC, Matsuura T, Tabe S and Ismail AF. Preparation and characterization of electro-spun nanofiber membranes and their possible applications in water treatment. Seperation and Purification Technology. 2013; 102:118-135. http://dx.doi.org/10.1016/j.seppur.2012.09.037

5. Wu S, Li F, Wang H, Fu L, Zhang B and Li G. Effects of poly (vinyl alcohol) (PVA) content on preparation of novel thiolfunctionalized mesoporous $\mathrm{PVA} / \mathrm{SiO}_{2}$ composite nanofiber membranes and their application for adsorption of heavy metal ions from aqueous solution. Polymer. 2010; 51:6203-6211. http://dx.doi.org/10.1016/j.polymer.2010.10.015

6. Hota G, Kumar BR, Ng WJ and Ramakrishna S. Fabrication and characterization of a boehmite nanoparticle impregnated electrospun fiber membrane for removal of metal ions. Journal of Materials Science. 2008; 43(1):212-217. http://dx.doi. org/10.1007/s10853-007-2142-4

7. Lee HW, Karim MR, Ji HM, Choi JH, Ghim HD, Park $\mathrm{SM}$ et al. Electrospinning fabrication and characterization of poly(vinyl alcohol)/montmorillonite nanofiber mats. Journal of Applied Polymer Science. 2009; 113:1860-1867. http://dx.doi. org/10.1002/app.30165

8. Galya T, Sedlarik V, Kutritka I, Novotny R, Sedlarikova J and Saha, P. Antibacterial poly(vinyl alcohol) film containing silver nanoparticles: preparation and characterization. Journal of Applied Polymer Science. 2008; 110:3178-3185. http://dx.doi. org/10.1002/app.28908

9. Hong KH. Preparation and properties of electrospun poly(vinyl alcohol)/silver fiber web as wound dressings. Polymer Engineering and Science. 2007; 47(1):43-49. http://dx.doi. org/10.1002/pen.20660

10. Sang YM, Li FS, Gu QB, Liang CZ and Chen JQ. Heavy metalcontaminated groundwater treatment by a novel nanofiber membrane. Desalination. 2008; 223:349-360. http://dx.doi. org/10.1016/j.desal.2007.01.208

11. Haider S and Park SY. Preparation of the electrospun chitosan nanofibers and their applications to the adsorption of $\mathrm{Cu}$ (II) and $\mathrm{Pb}(\mathrm{II})$ ions from an aqueous solution. Journal of Membrane Science. 2009; 328:90-96. http://dx.doi.org/10.1016/j. memsci.2008.11.046

12. Demir MM, Özen B and Özcelik S. Formation of Pseudoisocyanine J-Aggregates in Poly(vinyl alcohol) Fibers by Electrospinning. The Journal Physical Chemistry B. 2009; 113:11568-11573. PMid:19845394. http://dx.doi.org/10.1021/ jp902380n

13. Peng Q, Sun XY, Spagnola JC, Saquing C, Khan SA and Spontak RJ. Bi-directional Kirkendall Effect in Coaxial Microtube Nanolaminate Assemblies Fabricated by Atomic Layer Deposition. ACS Nano. 2009; 3:546-554. PMid:19222233. http://dx.doi.org/10.1021/nn8006543

14. Shao CL, Kim HY, Gong J, Ding B, Lee DR and Park SJ. Fiber mats of poly(vinyl alcohol)/silica composite via electrospinning. Materials Letters. 2003; 57:1579-1584. http:// dx.doi.org/10.1016/S0167-577X(02)01036-4

15. Taylor G. Electrically Driven Jets. Proceedings of the Royal Society London Series A. 1969; 313:453-475. http://dx.doi. org/10.1098/rspa.1969.0205

16. Mahanta N and Valiyaveettil S. Surface modified electrospun poly(vinyl alcohol) membranes for extracting nanoparticles from water. Nanoscale. 2011; 3:4625-4631. PMid:21904762. http://dx.doi.org/10.1039/c1nr10739a

17. Islam MdS, Karim MR. Fabrication and characterization of poly(vinyl alcohol)/alginate blend nanofibers by electrospinning method. Colloids and Surface A. 2010; 366:35-140.

18. Sasipriya K, Suriyaprabha R, Prabu P and Rajendran V. Synthesis and characterisation of polymeric nanofibers poly (vinyl alcohol) and poly (vinyl alcohol)/silica using indigenous electrospinning set up. Materials Research. 2013; 16(4):824830. http://dx.doi.org/10.1590/S1516-14392013005000050

19. Bae JA, Hwang SH, Song KC, Jeon JK, Ko YS and Yim JH. Synthesis of Functionalized Mesoporous Material with Various Organo-Silanes. Journal of Nanoscience and Nanotechnology. 2010; 10:290-296. http://dx.doi.org/10.1166/ jnn.2010.1495

20. Sakka S and Almedia RM. Handbook of Sol-gel Science and Technology. In: Processing, Characterization and Applications. Massachusetts: Kluwer Academic Publishers; 2005. v. 2, chapt. 7, p. 140-147.

21. Thanganathan U. Effects of imidazole on the thermal and conductivity properties of hybrid membrane based on poly(vinyl alcohol)/SiO ${ }_{2}$. Journal of Materials Chemistry. 2012; 22:96849689. http://dx.doi.org/10.1039/c2jm30975k

22. Mishra R and Rao KJ. On the formation of poly(ethyleneoxide)poly(vinylalcohol) blends. European Polymer Journal. 1999; 35:1883-1894. http://dx.doi.org/10.1016/S00143057(98)00283-3

23. Rajendran S, Sivakumar M and Subadevi R. Effect of salt concentration in poly(vinyl alcohol)-based solid polymer electrolytes. Journal of Power Sources. 2003; 124:225-230. http://dx.doi.org/10.1016/S0378-7753(03)00591-3

24. Stefănescu M, Stoia M, Stefănescu O, Davidescu C, Vlase G and Sfîrloagă P. Synthesis and caracterization of poly(vinylalcohol)/ethylene glycol/silica hybrids. Thermal analysis and FT-IR study. Revue Roumaine Chimie. 2010; 55(1):17-23. 